\title{
Lusioersily
}

\section{The Psychometric Properties and Factor Structure of the Antisocial Process Screening Device Self-Report Version in Chinese Adolescents}

Wang, M-C., Deng, Q., Armour, C., Bi, X., \& Zeng, H. (2015). The Psychometric Properties and Factor Structure of the Antisocial Process Screening Device Self-Report Version in Chinese Adolescents. Journal of Psychopathology and Behavioral Assessment, 37(4), 553-562. https://doi.org/10.1007/s10862-015-9486-x

Link to publication record in Ulster University Research Portal

Published in:

Journal of Psychopathology and Behavioral Assessment

Publication Status:

Published (in print/issue): 01/01/2015

DOI:

10.1007/s10862-015-9486-x

Document Version

Author Accepted version

\section{General rights}

Copyright for the publications made accessible via Ulster University's Research Portal is retained by the author(s) and / or other copyright owners and it is a condition of accessing these publications that users recognise and abide by the legal requirements associated with these rights.

\section{Take down policy}

The Research Portal is Ulster University's institutional repository that provides access to Ulster's research outputs. Every effort has been made to ensure that content in the Research Portal does not infringe any person's rights, or applicable UK laws. If you discover content in the Research Portal that you believe breaches copyright or violates any law, please contact pure-support@ulster.ac.uk. 
The psychometric properties and factor structure of the Antisocial Process

\title{
Screening Device self-report version in Chinese adolescents
}

\begin{abstract}
The present study examined the factor structure, internal consistency and criterion validity of the Antisocial Process Screening Device-Self-Report (APSD-SR) in a large sample of Chinese community youth with an average age of $13.89(S D=1.27)$ years. Both exploratory and confirmatory factor analysis supported a four factor solution (Impulsivity [IMP], Callous-Unemotional [CU], Narcissism [NAR], and Asocial behavior [ASO]). The internal consistencies of the APSD total scale and subscales were low to marginal, which were comparable with previous studies. Moreover, the APSD scores were related to criterion variables in ways consistent with predictions based on the new four-factor model. Our findings support the overall utility of the APSD-SR preliminarily for assessing antisocial behavior and psychopathic traits in Chinese community youth.
\end{abstract}

Keywords: psychopathy, APSD, self-report, psychometrics, Chinese youth 


\section{Introduction}

Psychopathy is a personality disorder consisting of interpersonal (e.g., manipulative, egocentric), affective (e.g., lack of empathy and emotions), and behavioral (e.g., impulsive, irresponsible and easily bored) traits. Psychopathic traits in childhood are strongly related to such traits in adulthood; both in regard to genetic components (Viding et al., 2005) and measurements (Burke et al., 2007).

The extension of the construct of psychopathy from adulthood to adolescence and childhood is a controversial issue (Edens \& Vincent, 2008; Silk, 2008). Developmental theorists have doubted the stability of psychopathic tendencies in childhood. Moreover, there have been a number of criticisms related to using psychopathy measures which were originally designed for adult populations in child/adolescents populations (Johnstone \& Cooke, 2004). However, the early identification of psychopathic tendencies contributes to our understanding of the etiology of psychopathy and thus may help to identify and elucidate who is in need of a unique approach to treatment (Forth et al., 1990). It is also noteworthy that the development of valid instruments for psychopathic traits in youth is considered critically important (Petrila \& Skeem, 2003). However, it was not until 1990 that attention was given to psychopathic traits in youth. Forth, Hart and Hare (1990) first adapted the Psychopathy Checklist (PCL; Hare, 1991) in a sample of adolescent offenders; this demonstrated that psychopathic traits could be identified in adolescents. The subsequent growth in the application and use of psychopathic 
measurements across different age groups has steadily increased (Forth et al., 1990; Kotler \& McMahon, 2010; Lynam, 1997; Salekin, 2006; Skeem et al., 2011). As a result of these efforts, the last decade has witnessed an emergence of numerous publications concerning youth psychopathy (Salekin \& Lynam, 2010).

The two most widely utilized measures are the Psychopathy Checklist-youth version (PCL-YV, Forth, Kosson \& Hare, 2003) and the Antisocial Process Screening Device (APSD; Frick \& Hare, 2001). The PCL-YV has primarily been used in incarcerated samples of adolescents (aged 12 to 18) and utilizes a 60-90 min semi-structured interview. It is therefore, a time-consuming instrument and not appropriate for use in larger scale community samples.

The APSD is a 20-item rating scale including both parent and teacher versions (Frick \& Hare, 2001). The APSD was originally modeled after the Psychopathy Checklist-Revised (PCL-R; Hare, 2003). However, given that scales which are composed of psychopathy traits include items reflecting personal feelings, it is questionable as to whether parents and teachers can assess them accurately.

Frick, Barry and Bodin (2000) indicated that "self-report becomes more reliable and valid as a child enters adolescence, especially for assessing antisocial tendencies and attitudes that may not be observable to parents and other significant adults" (p. 13). Thus, Caputo, Frick and Brodsky (1999) developed a self-report version of the APSD by converting items from the third to first person (e.g., "I blame others for my mistakes"). It can be administered to youths between 13 and 18 years old (Goodwin et al., in press). After analyzing previous studies, Munoz and Frick 
(2007) proposed four reasons as to why self-report accounts of adolescents' affective and behavioral dimensions were superior to accounts put forth by others. The reasons included socially desirable answering by parents and teachers of adolescents (Edens et al., 2001), low correlations between parents and child ratings though regarded as high in the assessment of childhood psychopathology (Achenbach, McConaughy \& Howell, 1987; Funder, Kolar \& Blackman, 1995), less stability of the self-report ratings than the parents' ratings (Frick et al., 2003), and the Impulsivity and Narcissism dimensions behaving quite different in parent and child ratings, as the antisocial behavior most strongly correlated with impulsivity in parent-report (Poythress, Dembo et al., 2006) but with narcissism in child-report (Burns, 2000). Furthermore, as noted by Falkenbach et al. (2003), some items written in second person (e.g., "Your emotions are shallow and fake") may lead to an inconsistent or defensive responding.

Although the APSD-SR has been widely used, there are some existing concerns. One such concern relates to the lack of agreement on the factor structure. Therefore it is important that the underlying dimensionality of this measure is examined across various samples in which it has been administered. Using clinical samples, Frick and colleagues (Frick et al., 1994) initially identified two factors within the APSD (teacher and parent version), Impulsivity and Conduct Problems (I/CP) and Callous-Unemotional traits (CU). Recently, Pechorro et al. (2013) supported the same two-factor solution in a Portuguese sample of community and incarcerated youth, utilizing the self-report version. Frick, Bodin and Barry (2000), utilizing a 
large US sample with both community and clinical children, reported a three-factor model; this included the CU factor in addition to factors composed of Narcissistic (NAR) and Impulsive (IMP) traits. Using the self-report version, the three-factor model has been replicated in offender samples (Spain et al., 2004; Vitacco, Rogers \& Neumann, 2003), a Flemish community sample (Bijttebier \& Decoene, 2009), and a sample of 4855 Finnish community adolescents (Laajasalo et al., 2014).

Still, two- and three-factor models mentioned above are found in recent studies with clinical (Fite et al., 2009) and community samples (de Wied et al., 2014; McMahon et al., 2010). In addition, it has been suggested that the structure of the APSD is similar but not identical across cultures, however studies to date have mainly focused on samples of western countries (e.g., Bijttebier \& Decoene 2009).

To the best of our knowledge, the factor structure of the self-report version of the APSD has not been examined in Chinese samples. Hence, the first aim of the present study was to examine the factor structure of the APSD-SR in a large sample of Chinese youth. It is believed that a replication of the factor structure will increase confidence in the use of the screening device within China.

An additional consideration of the APSD-SR relates to the internal consistency of its component scales (NAR, IMP and CU). Indeed, this has been questioned in several studies (de Wied et al., 2014; Laajasalo et al., 2014; Munoz \& Frick, 2007; Poythress, Douglas et al., 2006). Across studies the internal consistency of the factors has been reported as being modest to good; this is with the exception of the Callous-Unemotional factor (de Wied et al., 2014; Laajasalo et al., 2014; Poythress, 
Douglas et al., 2006). Poythress, Douglas et al. (2006) however stated that it is unnecessary to extend the number of items which represent the Callous-Unemotional factor. Of note, the fifth version of the Diagnostic and Statistical Manual of Mental Disorders (DSM-5; APA, 2013), specifies Callous-Unemotional features, composed of psychopathy, within childhood conduct disorder. This development within the DSM-5 embodies the importance of this body of research. Consequently, examining the internal consistency of the self-report version of the APSD is pertinent within the study of psychopathy.

The second aim of the study was therefore to examine the internal consistency of the APSD-SR by computing Cronbach's alpha coefficients and mean interitem correlation (MIC) for each scale in a sample of Chinese adolescents. Thus, based on issues highlighted herein, the aim of the present study was to examine the psychometric properties of the self-report version of the APSD in a community sample of Chinese adolescents by testing its factor structure, internal consistency and validity. Doing so will assess the functionality of this measure as it relates to predicting anti-social and delinquent behaviors in adolescents.

\section{Method}

\section{Participants}

In the present study, two separate samples were used. The first sample was used for exploratory factor analysis; Confirmatory Factor Analysis was conducted in the second sample. Two samples received different versions of the inventory, which 
consist of different scales (see below).

Sample one

The first sample consisted of 1607 participants recruited from one middle school, their ages ranged from 11 to 19 years, with a mean age of $14.66(S D=1.64)$ years, male $\left(n=727, M_{\text {age }}=14.74, S D=1.59\right)$ and female $\left(n=720, M_{\text {age }}=14.74\right.$, $S D=1.68)$. With regard to racial distribution, $95.7 \%$ of the participants were Han.

Sample two

A total of 501 participants were recruited from another middle school, ages ranged from 11 to 15 years, with a mean age of $13.12(S D=.90)$ years, male $(n=267$, $\left.M_{\text {age }}=13.17, S D=.92\right)$ and female $\left(n=231, M_{\text {age }}=13.06, S D=.87\right)$, among which $99.4 \%$ are Han.

\section{Procedure}

Participants completed the survey in school during a specified class period lasting approximately 40 minutes. Informed consent was given by parents (or legal guardians) prior to the administration of the self-reported questionnaires. Furthermore, children provided assent for their own participation. This study underwent a review by the Human Subjects Review Committee at Guangzhou University.

\section{Measures}

\section{Antisocial Process Screening Device-Self-Report Version (APSD-SR)}

The APSD-SR (Frick \& Hare, 2001) is a 20-item antisocial behavior and psychopathic traits measure designed for administration in youths. Each item is scored on a 3-point likert scale, ranging from 0 (not at all true) to 2 (definitely true). Previous 
studies have supported the validity of the APSD-SR in samples of children and adolescents (Colins et al., 2014; de Wied et al., 2014; Pechorro et al., 2013). The original scale comprised of Callous Unemotional (CU), Narcissistic (NAR) and Impulsive (IMP) subscales. A new factor pertaining to asocial behavior (ASO) was found in this study. The reliability alphas of the total scale and subscales CU, NAR, IMP and ASO in the current study were $.637, .504, .556, .575$ and .416 , respectively. But previous studies reported higher reliability coefficients (Fite et al., 2009; Frick \& Hare, 2001). Two samples completed this scale.

\section{Youth Psychopathic Traits Inventory (YPI)}

The YPI (Andershed et al., 2002) is a self-report measure designed for administration within youth samples. The YPI consists of 50 items, which are divided across 10 different sub-scales; each containing 5 items. Each item was answered on a 4-point Likert-type scale ranging from 0 (does not apply at all) to 3 (applies very well). The ten scales represent Dishonest charm, Grandiosity, Lying, Manipulation, Remorselessness, Unemotionality, Callousness, Thrill-seeking, Impulsiveness, and Irresponsibility. These 10 sub-scales reflect three broader domains; Callous-Unemotional, Grandiose-Manipulative, and Impulsive-Irresponsible, corresponding to the three dimensions of Cooke and Michie (2001; e.g., affective, interpersonal and lifestyle dimensions). A previous study reported good Cronbach's alphas for all ten subscales with the exception of three (Grandiosity, Unemotionality, and Callousness). Reliability alphas ranged from .47 (Callousness) to .81 (Dishonest charm) (Colins et al., 2014). In the current study, internal consistency was good for 
the YPI total score $(\alpha=.892)$, and acceptable for most subscales, ranging from .469 (Unemotionality) to .720 (Grandiosity), with a median of .619. Two samples completed this scale.

Both the Chinese versions of the APSD-SR and YPI were translated into Chinese and back translated into English to ensure accuracy. To reach an agreement of the comprehension of all items, further discussions had been conducted several times. To assess the readability of the translated versions, the questionnaire was then piloted in samples of middle school students who were independent of formal participants.

\section{The Youth Self-Report (YSR)}

Two subscales from the YSR were included in the current study; Rule-Breaking Behavior (RB, 13 items) and Aggressive Behavior (AGG, 20 items). These questions were answered on a 3 -point scale $(0=$ never true, $1=$ sometimes true, $2=$ always true $)$. Excellent psychometric properties have been reported for the Chinese version, including strong test-retest reliability, inter-parent agreement, internal consistency, and high construct validity (Leung et al., 2006). In the present study, the Cronbach's alphas for the total score of the YSR was .871, and for RB and AGG were .672 and .841. Only sample one completed this scale.

\section{The Reactive-Proactive Aggression Questionnaire (RPQ)}

The RPQ (Raine et al., 2006) is a 23-item questionnaire comprising 12 items which assess proactive aggression and 11 items which assess reactive aggression. In the self-report version, people are asked about reasons of their aggressive behaviors. Questions are not restricted to events which have occurred in the past few months. 
Each item was answered on a 3-point Likert-type scale, ranging from 0 (never) to 2 (often). Good internal consistency and construct validity was reported for RPQ in Chinese sample (Fung, Raine \& Gao, 2009). Internal consistency reliability for the present study was good $($ RPQ total $=.859$, Reactive $=.807$, Proactive $=.797)$. Only sample two completed this scale.

\section{Analytical Plan}

Given the lack of consensus within the extant literature, as it relates to the factor structure of the APSD, it was appropriate to first conduct exploratory factor analyses (EFA) and then subsequently conduct confirmatory factor analyses (CFA).

\section{Exploratory Factor Analysis (EFA)}

Descriptive statistics and EFA were performed by the SPSS program (IBM, SPSS version 17, 2009). Principal components analysis with direct Oblimin rotation was undertaken. Loadings greater than or equal to .30 were presented. The parallel analysis which was thought be to the best way to decide number of factors (Fabrigar, Wegener, MacCallum \& Strahan, 1999) as well as the scree plot and eigenvalue criteria was used to determine the number of factors.

\section{Confirmatory Factor Analysis (CFA)}

CFA was performed using Mplus7.0 (Muthén \& Muthén, 1998-2010). Given that items have only three response categories, Maximum Likelihood (ML) estimation was deemed inappropriate in light of simulations studies showing that a minimum of five response categories are a prerequisite to the assumptions of continuity underlying ML estimation (DiStefano, 2002; Lubke \& Muthén, 2004). 
Thus, items were treated as categorical and the robust weighted least-squares with mean and variance adjustment (WLSMV) estimator was used in present study (Flora \& Curran, 2004).

Following generally accepted practice, we evaluated the fit of each model by examining multiple fit indices (Kline, 2010). We used the Chi-square, root-mean-square error of approximation (RMSEA), Tucker-Lewis index (TLI) and comparative fit index (CFI). Conventional guidelines suggest that RMSEA values $\leq .08$ indicate acceptable model fit and $\leq .05$ indicate good model fit, and CFI, TLI $\geq .90$ indicate adequate model fit (Kline, 2010).

\section{Results}

\section{Exploratory Factor Analysis (EFA)}

The results of scree plot, parallel analysis and eigenvalue criteria suggested the retention of four factors. The eigenvalues of the estimated correlation matrix equals to the random data generated eigenvalues through the first four factors (first five empirical eigenvalues $=2.45,1.47,1.33,1.15$ and 1.10 ; first five random data eigenvalues $=1.23,1.19,1.17,1.14$ and 1.11), suggesting four factors should be considered. The four-factor solution cumulatively accounted for $37.17 \%$ of the total variance. All items primarily loaded on target factors, except for item 16 (thinks s/he is better or more important than others) which loaded on at least two factors (IMP and CU) with loadings of .347 and .310 , respectively. After removing item 16, the four-factor model accounted for $38.19 \%$ of the total variance. After this change, item 14 which loaded on $\mathrm{CU}$, changed from .339 to .308 . In terms of the concept and 
strength of the loading, item 14 (charming in insincere way) was included in the Narcissism traits. All rotated factor loadings and communalities are presented in Table 1.

Items of the first factor (items $4,17,1,15,11,13$ ) reflected Impulsivity (e.g., act without thinking, engage in risky moves). The second factor (items 3, 12, 18, 7, reversed scored) reflected Callous-Unemotional traits (e.g., care about others feelings, keep promises). The third factor, described as Asocial behavior (ASO) in the current study, was composed of item 20, item 19 and item 9 with negative loadings, which is new in the study of psychopathy. And the final factor (items 10, 8, 6, 14, 2, 5) reflected Narcissism traits (e.g., tease others, lies skillfully).

All items have low communalities (i.e., lower than .50) except for item 19, suggesting that these items have less in common, but communalities in different factors showed little differences, ranging from .229 to .441 for the Impulsivity-factor, .327 to .469 for the Callous-Unemotional factor, .257 to .493 for the Narcissism-factor and .349 to .543 for the Asocial factor. Strictly speaking, communalities for the Asocial factor were higher than the others, thereby supporting the robustness of this factor as a separate dimension.

\section{Confirmatory Factor Analysis (CFA)}

The four factor solution found in the EFA in this study, as well as the single factor model and the second-order model of the four-factor model, and the three-factor model recommended by Frick and Hare (2001) were evaluated. Items distributing to factors of the four-factor model were described in the EFA section. 
Items consisting of factors of the three-factor model were as followed: the NAR factor were composed by items $5,8,10,11,14,15$ and 16; the IMP factor consisted of items 1, 4, 9, 13 and 17; and the CU factor included items 3, 7, 12, 18, 19 and 20. Results indicated that the four factor model fitted the data reasonably well (see Table 2). The three factor model, excluded items 2 and 6 consistent with Frick and Hare (2001), was then estimated, resulting in poorer fit. Factor loadings resulted from the CFA were also presented in Table 1. Though none of the results met the fit criteria of the CFI or the TLI which requires values greater than .90 , to indicate good fit (Kline, 2010), the fit of the four-factor model was better than the other three models.

\section{Internal Consistency}

After identifying the most appropriate factor solution, alpha coefficients (Cronbach, 1951) were calculated to assess internal consistency for the total score and each subscale score. Given that Cronbach's alpha depends on interitem correlations and number of items, we also calculated mean interitem correlations (MIC) which are independent of scale lengths. Clark and Watson (1995) indicated that MIC values should be in the range of .15 to .50 . The MICs in the current study were acceptable for subscales of IMP (.186), CU (.204), NAR (.181) and ASO (.197), but the MIC value for total score of the APSD-SR was .092.

Based on the perception that Chinese students are more conditioned to schools and consider all students in the same class as friends, the original meaning of item 20 (keeps the same friends, stressing maintaining friendship) was retranslated to stressing and maintaining only a few of the same friends. In the current study, item 20 was not 
reversed scored, because students pay more attention to the meaning of only a few friends when interviewed after finishing the questionnaires. Therefore, in line with most studies, item 3, item 7, item 12 and item 18 were reversed scored, whereas item 20 was positive scored.

Internal consistencies, means and standard deviations (see Table 3) were computed for all APSD and criteria validity scales. The internal consistencies of most of the resulting scales are high, whereas the Cronbach's alphas of the APSD-SR subscales are below a level of considered acceptable. For the Callousness factor of YPI, item 12 was removed according to the value of Cronbach's alpha if item was deleted when reliability analysis was conducted. All MIC values were in the suggesting range of .15 to .50 , except value of the total score of APSD-SR (.092).

The internal consistency of the APSD factors was in the low to moderate range, with the following alphas, $\mathrm{CU}=.504, \mathrm{NAR}=.556, \mathrm{IMP}=.575$, and total APSD $=.637$. These coefficients are generally consistent with most of previous studies (Munoz \& Frick, 2007; Poythress, Douglas et al., 2006).

Correlations were statistically significant among the four factors of APSD-SR (see Table 4), except correlation between IMP and CU factors $(.036, p>.05)$. In the current study, correlations between $\mathrm{CU}$ factor and ASO were very low, but statistically significant $(r=-.069, p<.01)$.

\section{Criterion Validity}

Additionally, correlations between the APSD total scores and its factors with external criteria are shown in Table 4. As expected, the Impulsivity factor was 
strongly correlated with traits of Thrill-seeking, Impulsiveness and Irresponsibility ( $r$ $=.467, .555$ and $.419, p s<.01$, respectively). The Narcissism factor showed strong correlations with Dishonest Charm, Lying, and Manipulation factors with the correlations of $.466, .495$ and .452 , respectively. Although the Asocial factor was not highly correlated with psychopathic features of YPI, it was significantly correlated, ranging from -.050 to .241 . The $\mathrm{CU}$ traits did not significantly correlate with Unemotionality $(r=.026, \mathrm{~ns})$ and Thrill-seeking $(r=.004, \mathrm{~ns})$. Meanwhile, the CU traits were negatively correlated with Grandiosity $(r=-.02, \mathrm{~ns})$.

Further, the APSD-SR total scores and its subscales, excluding CU, showed significant correlations with symptoms measured by the YSR. As expected, correlations between Impulsivity and Narcissism factors with subscales of the YSR were significantly moderate to strong, ranging from .413 to $.525, p$ s $<.01$. The CU factor had low correlations with corresponding scores on the YSR. The CU correlated with Rule-Breaking behavior at $r=.124(p<.01)$, with Aggressive behavior at $r=$ -.003 , and with YSR total scale at $r=.04$, both were non-significant. Similar to correlations with YPI, correlations between the Asocial factor and factors composed of YSR were low compared to Impulsivity and Narcissism factors, but significant ( $p s$ $<.01)$.

The total score of APSD-SR was significantly correlated with RPQ total scale and two subscales $(r=.528, r=.397$ and $r=.507, p$ s $<.01$, respectively), whereas low and nonsignificant correlations were shown between correlations of CU with Reactive $(r=.079, p>.05)$ and ASO with Proactive $(r=.017, p>.05)$. However, CU was 
significantly correlated with proactive aggression $(r=.223, p<.01)$, and ASO was significantly correlated with reactive aggression $(r=.177, p<.01)$. The IMP and NAR factors were strongly correlated with factors of RPQ, ranging from .317 to .549 , ps $<.01$.

\section{Comparison of Gender Differences}

The subscale and total scale mean scores of APSD-SR are reported in Table 5 by gender groups. Boys reported higher scores on the CU subscale $(t=5.95 ; p<.05$; $d=.30)$ and NAR subscale $(t=8.16 ; p<.05 ; d=.42)$, whereas girls reported higher scores on the ASO subscale $(t=-3.08 ; p<.05 ; d=-.16)$. There were no gender differences in regard to the IMP subscale.

\section{Discussion}

The purpose of the current study was to test the psychometric properties and factor structure of APSD-SR among a relatively large sample of Chinese community adolescents. Our findings provide some preliminary support for the psychometric properties and construct validity of the APSD-SR in Chinese youth.

Given that the factor structure of the APSD-SR was retained from the original, the first aim was to conduct an exploratory factor analysis. Results provided support for a four-factor structure within a large sample of Chinese community youths. For the present study, items 1, 4, 13 and 17, composed of the Impulsivity factor, were the same items originally used for this factor by Frick and Hare (2001) who revised the APSD-SR. The other two items 11 (tease or make fun of others) and 15 (becomes 
angry when corrected), composed of the Narcissism factor in the original revision, were loading on the Impulsivity factor, which was acceptable according to their concept and loadings.

Six items (items 3, 7, 12, 18, 19 and 20) were initially attributed to the Callous-Unemotional factor reported by Frick and Hare (2001), of which only the former four items were included, namely, items 19 and 20 did not belong to this factor in the current study. Previous studies indicated that at least one of the items, of items 19 and 20 were inconsistent with the CU factor, and suggestions have been made to either eliminate or revise them (Laajasalo et al., 2014; Eremsoy et al., 2011; Poythress, Dembo et al., 2006; Poythress, Douglas et al., 2006). However, for the present study, both item 19 and item 20 were included in the new factor, the Asocial behavior factor, along with item 9 (gets bored easily). Poor results of item 19 and item 20 might be due to the expression of those items being unclear thus participants might not have captured their meaning adequately. Take item 19 (shows no emotions) for example. If it was described as "Hiding feelings and emotions from others", it may suggest that the emotional channels of communication are damaged which are associated with interpersonal relationships (Munoz \& Frick, 2007), whereas the description of "Does not show emotions" might suggest a lack of reactions of emotions which one does not trigger or hide deliberately (Fite et al., 2009; Laajasalo et al., 2014). In the current study, we take the first description due to its univocal characteristic. Moreover, to make it easy to capture the meaning of item 20 (maintains same friends, stressing keeping friendship, reversed score), we retranslated it to highlight a few long-term 
friends (positive score), because it's hard for Chinese students to tell clearly what friends mean to them and some might take students in the same class as their friends. Of note, our retranslation still indicates difficulties in attachment and distrust or insecurity to maintain social relationships, a potentially developmental precursor to psychopathy.

Four items (items 5, 8, 10 and 14) remained in the initial factor, the Narcissism factor, with item 2 and item 6. Loadings attributed to relevant factors were clear and stable. Few changes were evident when item 16 was removed, however there was improvement in the total explained variance. The current study was the first to date to support a four-factor structure in a large sample of Chinese community youth. Further studies are encouraged to recruit other samples in order to extend the generalizability of these results.

The second aim for the present study was to examine the internal consistency, estimated by Cronbach's alpha (Cronbach, 1951) and mean interitem correlations (MIC). Results showed that the internal consistency indices of the APSD total scale and subscales were low to marginal, which in line with most previous studies (e.g., Munoz \& Frick, 2007; Poythress, Douglas et al., 2006; Vitacco et al., 2003). For example, alphas in the study of Vitacco et al. (2003) were IMP $=.53, \mathrm{CU}=.59, \mathrm{NAR}$ $=.74$, and Total $=.62$. It was disappointing that the internal consistency was poor with such a large sample, whereas other scales, measured for criteria validity concurrently, generally showed good to acceptable values. Although alphas for the APSD subscales were under the acceptable level, their MIC values were all within the 
recommended range.

The weak reliability of the APSD-SR may be because the instrument was derived from the APSD, and thus initially designed to be answered by parents or teachers with plain description (e.g., brags about accomplishments).Therefore it might cause adolescents to become defensive when answering the items or it might be hard for youths to fully understand the concept of the items, especially for students who are short of social or life experience. Another possibility is the complexity of affective features. As it is known, behavioral features are always concrete and observable, whereas affective traits may depend on different conditions and it is hard to convey this in only a few words during a short time.

To further examine the usefulness of the self-report measure, criteria validity was considered in the current study. Overall, the CU and ASO factors significantly correlated with each other with negative low values, and showed weak correlations with the criteria scales. It seems that correlations with the CU factor were low when compared to other subscales of the APSD-SR. For example, the CU factor showed lower correlations with total and subscales of the YSR. However, in terms of the CU traits, correlations were significant with proactive aggression and total score of aggression, but not with reactive aggression. In Goodwin et al.'s (in press) study, the APSD Callousness was significantly correlated with the two subscales of the RPQ, but the standardized beta weight was only statistically significant with proactive aggression $(\beta=.23 . p<.01)$. In terms of the ASO factor, correlations were significant with reactive aggression and total aggression, but not with proactive aggression. 
These associations may be explained that people with asocial behavior might not aggress others actively or instrumentally. However, when they were irritated or annoyed by others, they would react aggressive behavior. As the ASO factor was first reported, further studies should be made to further clarify our findings.

In relation to gender differences, boys reported higher levels of CU traits, which is consistent with the study of de Wied et al. (2014). With regard to this result, O' Kearney and Dadds (2010) proposed that girls are more inclined to share inner feelings with others compared to boys. Unexpectedly, boys reported lower levels of asocial behavior than girls. This is quite puzzling because girls are more inclined to share inner feelings than boys (de Wied et al., 2014). However, it can also be due to the sensitivity of inner feelings of girls who would regard slight changes of their emotions as serious. As reported by de Wied et al. (2014) and Frick et al. (2003), boys indicated higher scores than girls on I/CP or IMP and NAR. In the current study, the result of NAR on gender differences were similar.

The current study is the first to use the APSD to report the psychopathic traits, of Chinese adolescents, thus more investigations are needed to further elucidate this and to expand on the current findings.

Several limitations need to be declared in this study. A limitation of this study was its homogeneous sample. This study only examined the psychometric properties of the APSD-SR in two sample of Chinese community youth. Variances of the obtained scores were limited, which would affect the Cronbach's alpha coefficients. Future studies should be made in clinic-referred and incarcerated samples to support 
its robustness. Additionally, this study relied on self-report for both APSD scale and other validity scales. Correlations could be inflated by shared method variance with all instruments being self-report. What's more, measurements assessing psychopathy in self-report have often been criticized (Edens et al., 2000; Lilienfeld et al., 2006). However, most recent studies have shown that self-report assessments of psychopathy features were reliable and valid (e.g., Ray et al., 2013; Vahl et al., 2014). Future studies should combine multi-informant methods and compare correlations across different observers to exam psychopathy features. Finally, this is cross-sectional research which could only show associations. Longitudinal studies are needed in the future.

In conclusion, the current study was the first to date to support a four-factor structure in a large sample of Chinese community youth. Further studies are encouraged to recruit other samples in order to extend their generalizability. Meanwhile, the present study replicated the difficulty in obtaining good internal consistency of the APSD-SR.

\section{References}

Achenbach, T. M. (1991). Manual for the youth self-report and 1991 profile. Burlington, VT: Department of Psychiatry, University of Vermont.

Achenbach, T. M., McConaughy, S. H., \& Howell, C. T. (1987). Child/adolescent behavioral and emotional problems: implications of cross-informant correlations for situational specificity. Psychological bulletin, 101, 213-232. 
doi:10.1037//0033-2909.101.2.213

American Psychiatric Association. (2013). Diagnostic and statistical manual of mental disorders (5th ed.). Arlington, VA: American Psychiatric Publishing.

Andershed, H., Kerr, M., Stattin, H., \& Levander, S. (2002). Psychopathic traits in non-referred youths: Initial test of a new assessment tool. In E. Blaauw \& L. Sheridan (Eds.), Psychopaths: Current international perspectives (pp. 131-158). The Hague, the Netherlands: Elsevier.

Bijttebier, P., \& Decoene, S. (2009). Assessment of psychopathic traits in children and adolescents: Further validation of the Antisocial Process Screening Device and the Childhood Psychopathy Scale. European Journal of Psychological Assessment, 25, 157-163. doi:10.1027/1015-5759.25.3.157

Burke, J. D., Loeber, R., \& Lahey, B. B. (2007). Adolescent Conduct Disorder and Interpersonal Callousness as Predictors of Psychopathy in Young Adults. Journal of Clinical Child \& Adolescent Psychology, 36, 334-346. doi:10.1080/15374410701444223

Burns, G. L. (2000). Problem of item overlap between the psychopathy screening device and attention deficit hyperactivity disorder, oppositional defiant disorder, and conduct disorder rating scales. Psychological Assessment, 12, 447-450. doi.10.1037/1040-3590.12.4.447

Caputo, A. A., Frick, P. J., \& Brodsky, S. L. (1999). Family violence and juvenile sex offending: The potential mediating role of psychopathic traits and negative attitudes toward women. Criminal Justice and Behavior, 26, 338-356. 
doi:10.1177/0093854899026003004

Clark, L. A., \& Watson, D. (1995). Constructing validity: Basic issues in objective scale development. Psychological assessment, 7, 309-319. doi:10.1037//1040-3590.7.3.309

Colins, O. F., Bijttebier, P., Broekaert, E., \& Andershed, H. (2014). Psychopathic-Like Traits among Detained Female Adolescents Reliability and Validity of the Antisocial Process Screening Device and the Youth Psychopathic Traits Inventory. Assessment, 21, 195-209. doi:10.1177/1073191113481997

Cooke, D. J., \& Michie, C. (2001). Refining the construct of psychopathy: towards a hierarchical model. Psychological assessment, 13, 171-188. doi:10.1037/1040-3590.13.2.171

Cronbach, L. J. (1951). Coefficient alpha and the internal structure of tests. psychometrika, 16, 297-334. doi:10.1007/BF02310555

de Wied, M., van der Baan, H., Raaijmakers, Q., de Ruiter, C., \& Meeus, W. (2014). Factor structure and construct validity of the Dutch version of the Antisocial Process Screening Device. Journal of Psychopathology and Behavioral Assessment, 36, 84-92. doi: 10.1007/s10862-013-9371-4

DiStefano, C. (2002). The impact of categorization with confirmatory factor analysis. Structural Equation $\quad$ Modeling, 9, 327-346. doi:10.1207/S15328007SEM0903-2

Edens, J. F., Hart, S. D., Johnson, D. W., Johnson, J. K., \& Olver, M. E. (2000). Use of the Personality Assessment Inventory to assess psychopathy in offender 
doi:10.1037/1040-3590.12.2.132

Edens, J. F., Skeem, J. L., Cruise, K. R., \& Cauffman, E. (2001). Assessment of "juvenile psychopathy" and its association with violence: a critical review*. Behavioral Sciences \& the Law, 19, 53-80. doi:10.1002/bs1.425

Edens, J. F., \& Vincent, G. M. (2008). Juvenile psychopathy: A clinical construct in need of restraint? Journal of Forensic Psychology Practice, 8, 186-197. doi:10.1080/15228930801964042

Eremsoy, C. E., Karanci, A. N., \& Berument, S. K. (2011). Psychometric Properties of the Antisocial Process Screening Device in a Non-Clinical Sample of Turkish Children. Procedia - Social and Behavioral Sciences, 30, 2319-2323. doi:10.1016/j.sbspro.2011.10.452

Fabrigar, L. R., Wegener, D. T., MacCallum, R. C., \& Strahan, E. J. (1999). Evaluating the use of exploratory factor analysis in psychological research. Psychological Methods, 4, 272-299. doi:10.1037/1082-989X.4.3.272

Falkenbach, D. M., Poythress, N. G., \& Heide, K. M. (2003). Psychopathic features in a juvenile diversion population: reliability and predictive validity of two self - report measures. Behavioral sciences \& the law, 21, 787-805. doi:10.1002/bsl.562

Fite, P. J., Greening, L., Stoppelbein, L., \& Fabiano, G. A. (2009). Confirmatory Factor Analysis of the Antisocial Process Screening Device with a Clinical Inpatient Population. Assessment, 16, 103-114. 
doi:10.1177/1073191108319893

Flora, D. B., \& Curran, P. J. (2004). An empirical evaluation of alternative methods of estimation for confirmatory factor analysis with ordinal data. Psychological methods, 9, 466-491. doi:10.1037/1082-989X.9.4.466

Forth, A. E., Hart, S. D., \& Hare, R. D. (1990). Assessment of psychopathy in male young offenders. Psychological Assessment: A Journal of Consulting and Clinical Psychology, 2, 342-344. doi:10.1037/1040-3590.2.3.342

Forth, A. E., Kosson, D. S., \& Hare, R. D. (2003). Hare Psychopathy Checklist-Revised: Youth Version. Toronto: ON, Multi-Health Systems.

Frick, P., Barry, C., \& Bodin, S. (2000). Applying the concept of psychopathy to children: Implications for the assessment of antisocial youth. In C. Gacono (Ed.), The clinical and forensic assessment of psychopathy: A practitioner's guide (pp. 1-24). Mahwah, NJ: Lawrence Erlbaum.

Frick, P. J., Bodin, S. D., \& Barry, C. T. (2000). Psychopathic traits and conduct problems in community and clinic-referred samples of children: Further development of the psychopathy screening device. Psychological Assessment, 12, 382-393. doi:10.1037/1040-3590.12.4.382

Frick, P. J. \& Hare, R. D. (2001). The antisocial process screening device. Toronto: Multi-Health Systems.

Frick, P. J., Kimonis, E. R., Dandreaux, D. M., \& Farell, J. M. (2003). The 4 year stability of psychopathic traits in non - referred youth. Behavioral Sciences \& the Law, 21, 713-736. doi:10.1002/bs1.568 
Frick, P. J., O’Brien, B. S., Wootton, J. M., \& McBurnett, K. (1994). Psychopathy and conduct problems in children. Journal of Abnormal Psychology, 103, 700707. doi:10.1037/0021-843X.103.4.700

Funder, D. C., Kolar, D. C., \& Blackman, M. C. (1995). Agreement among judges of personality: interpersonal relations, similarity, and acquaintanceship. Journal of personality and social psychology, 69, 656-672. doi:10.1037/0022-3514.69.4.656

Fung, A. L. C., Raine, A., \& Gao, Y. (2009). Cross-cultural generalizability of the reactive-proactive aggression questionnaire (RPQ). Journal of personality assessment, 91, 473-479. doi:10.1080/00223890903088420

Goodwin, B. E., Sellbom, M., \& Salekin, R. T. (in press). Elucidating the Construct Validity of the Antisocial Process Screening Device (APSD) in a Sample of Young Adults. Journal of Psychopathology and Behavioral Assessment. doi: $10.1007 / \mathrm{s} 10862-014-9444-\mathrm{Z}$

Hare, R. D. (1991). The Hare Psychopathy Checklist-Revised. Toronto, Ontario, Canada: Multi-Health Systems.

Hare, R. D. (2003). Hare psychopathy checklist-revised (PCL-R): Second edition, technical manual. Toronto, Canada: Mult-Health Systems.

IBM SPSS Inc. (2009). IBM SPSS Missing Values for Windows (Version 17). Armonk, NY: IBM.

Johnstone, L., \& Cooke, D. J. (2004). Psychopathic-like traits in childhood: Conceptual and measurement concerns. Behavioral sciences \& the law, 22, 
103-125. doi: 10.1002/bsl.577

Kline, R. B. (2010). Principles and practice of structural equation modeling (3rd ed.). New York, New York: Guilford Press.

Kotler, J. S., \& McMahon, R. J. (2010). Assessment of child and adolescent psychopathy. In R. T. Salekin\&D. R. Lynam(Eds.), Handbook of child \& adolescent psychopathy (pp. 79-109). New York London: The Guilford Press.

Laajasalo, T., Saukkonen, S., Kivivuori, J., Salmi, V., Lipsanen, J., \& Aronen, E. T. (2014). Self-reported psychopathic-like features among Finnish community youth: Investigation of the factor structure of the antisocial personality screening device. Journal of adolescence, 37, 1185-1188. doi:10.1016/j.adolescence.2014.08.010

Leung, P. W., Kwong, S. L., Tang, C. P., Ho, T. P., Hung, S. F., Lee, C. C., ... \& Liu, W. S. (2006). Test-retest reliability and criterion validity of the Chinese version of CBCL, TRF, and YSR. Journal of Child Psychology and Psychiatry, 47, 970-973. doi:10.1111/j.1469-7610.2005.01570.x

Lilienfeld, S. O., \& Fowler, K. A. (2006). The self-report assessment of psychopathy: Problems, pitfalls, and promises. In C. J. Patrick (Ed.), Handbook of psychopathy (pp. 107-132). New York, NY: Guilford Press.

Lubke, G. H., \& Muthén, B. O. (2004). Applying multigroup confirmatory factor models for continuous outcomes to Likert scale data complicates meaningful group comparisons. Structural Equation Modeling, 11, 514-534. doi:10.1207/s15328007sem1104-2 
Lynam, D. R. (1997). Pursuing the psychopath: Capturing the fledgling psychopath in a nomological net. Journal of Abnormal Psychology, 106, 425438. doi:10.1037/0021-843X.106.3.425

McMahon, R. J., Witkiewitz, K., \& Kotler, J. S. (2010). Predictive validity of Callous-Unemotional traits measured in early adolescence with respect to multiple antisocial outcomes. Journal of Abnormal Psychology, 119, 752-763. doi:10.1037/a0020796

Munoz, L. C., \& Frick, P. J. (2007). The reliability, stability, and predictive utility of the self-report version of the Antisocial Process Screening Device. Scandinavian Journal of Psychology, 48, 299-312. doi:10.1111/j.1467-9450.2007.00560.x

Muthén, L. K., \& Muthén, B. O. (1998-2010). Mplus user's guide (7th ed.). Los Angeles, California: Muthén \& Muthén.

O'Kearney, R., \& Dadds, M. (2004). Developmental and gender differences in the language for emotions across the adolescent years. Cognition and Emotion, 18, 913-938. doi:10.1080/02699930341000356

Pechorro, P., Maroco, J., Poiares, C., \& Vieira, R. X. (2013). Validation of the Portuguese version of the Antisocial Process Screening Device-Self-Report with a focus on delinquent behavior and behavior problems. International Journal of Offender Therapy and Comparative Criminology, 57, 112-126. doi:10.1177/0306624X11427174

Petrila, J., \& Skeem, J. L. (2003). An introduction to the special issues on juvenile 
psychopathy and some reflections on the current debate. Behavioral Sciences \& the Law, 21, 689-694. doi:10.1002/bs1.569

Poythress, N. G., Dembo, R., Wareham, J., \& Greenbaum, P. E. (2006). Construct validity of the Youth Psychopathic Traits Inventory (YPI) and the Antisocial Process Screening Device (APSD) with justice-involved adolescents. Criminal Justice and Behavior, 33, 26-55. doi:10.1177/0093854805282518

Poythress, N. G., Douglas, K. S., Falkenbach, D., Cruise, K., Lee, Z., Murrie, D. C., \& Vitacco, M. (2006). Internal Consistency Reliability of the Self-Report Antisocial Process Screening Device. Assessment, 13, 107-113. doi: $10.1177 / 1073191105284279$

Raine, A., Dodge, K., Loeber, R., Gatzke - Kopp, L., Lynam, D., Reynolds, C., \& Liu, J. (2006). The Reactive-Proactive Aggression Questionnaire: Differential correlates of reactive and proactive aggression in adolescent boys. Aggressive behavior, 32, 159-171. doi:10.1002/ab.20115

Ray, J. V., Hall, J., Rivera-Hudson, N., Poythress, N. G., Lilienfeld, S. O., \& Morano, M. (2013). The relation between self-reported psychopathic traits and distorted response styles: A meta-analytic review. Personality Disorders: Theory, Research, and Treatment, 4, 1-14. doi:10.1037/a0026482

Ribeiro da Silva, D., Rijo, D., \& Salekin, R. T. (2013). Child and adolescent psychopathy: Assessment issues and treatment needs. Aggression and violent behavior, 18, 71-78. doi:10.1016/j.avb.2012.10.003

Salekin, R. T. (2006). Psychopathy in children and adolescents: Key issues in 
conceptualization and assessment. In C. J. Patrick (Ed.), Handbook of psychopathy (pp. 389-414). New York, NY, US: Guilford Press.

Salekin, R. T., \& Lynam, D. R. (2010). Child and adolescent psychopathy: An introduction. In R. T. Salekin, D. R. Lynam (Eds.), Handbook of Child and Adolescent Psychopathy (pp. 1-11). New York, NY, US: Guilford Press.

Saltaris, C. (2002). Psychopathy in juvenile offenders: Can temperament and attachment be considered as robust developmental precursors? Clinical Psychology Review, 22, 729-752. doi:10.1016/S0272-7358(01)00122-2

Skeem, J. L., Polaschek, D. L., Patrick, C. J., \& Lilienfeld, S. O. (2011). Psychopathic personality: Bridging the gap between scientific evidence and public policy. Psychological Science in The Public Interest, 12, 95162. doi:10.1177/1529100611426706

Silk, K. R. (2008). Personality disorder in adolescence: The diagnosis that dare not speak its name. Personality and Mental Health, 2, 46-48. doi:10.1002/pmh.31

Spain, S. E., Douglas, K. S., Poythress, N. G., \& Epstein, M. (2004). The relationship between psychopathic features, violence and treatment outcome: the comparison of three youth measures of psychopathic features. Behavioral Sciences \& the Law, 22, 85-102. doi:10.1002/bsl.576

Vahl, P., Colins, O. F., Lodewijks, H. P., Markus, M. T., Doreleijers, T. A., \& Vermeiren, R. R. (2014). Psychopathic-like traits in detained adolescents: clinical usefulness of self-report. European child \& adolescent psychiatry, 23, 691-699. doi:10.1007/s00787-013-0497-4 
Viding, E., Blair, R. R., Moffitt, T. E., \& Plomin, R. (2005). Evidence for substantial genetic risk for psychopathy in 7-year-olds. Journal of Child Psychology \& Psychiatry, 46, 592-597. doi:10.1111/j.1469-7610.2004.00393.x

Vitacco, M. J., Rogers, R., \& Neumann, C. S. (2003). The Antisocial Process Screening Device: An examination of its construct and criterion-related validity. Assessment, 10, 143-150. doi:10.1177/1073191103010002005 
Table 1

Four-Factor Principal Components Analysis and CFA Loadings for the APSD-SR

\begin{tabular}{|c|c|c|c|c|c|}
\hline & & IMP & $\mathrm{CU}$ & NAR & COMM \\
\hline Item4 & Acts without thinking & $.674(.496)$ & & & .441 \\
\hline Item17 & Does not plan ahead & $.606(.468)$ & & & .421 \\
\hline Item1 & Blames others for mistakes & $.548(.472)$ & & & .331 \\
\hline Item15 & Becomes angry when corrected & $.544(.363)$ & & & .350 \\
\hline Item11 & Teases other people & $.450(.554)$ & & & .325 \\
\hline Item13 & Engages in risky and dangerous behavior & $.403(.538)$ & & & .229 \\
\hline Item 16 & thinks s/he is better or more important & .347 & .310 & & .346 \\
\hline Item3 & Concerned about schoolwork (R) & & $.662(.460)$ & & .446 \\
\hline Item18 & Concerned about feelings of others (R) & & $.611(.314)$ & & .469 \\
\hline Item12 & Feels bad or guilty $(\mathrm{R})$ & & $.569(.439)$ & & .385 \\
\hline Item7 & Keeps promises $(\mathrm{R})$ & & $.534(.733)$ & & .327 \\
\hline Item19 & Does not show emotions & & & $-.711(.580)$ & .543 \\
\hline Item20 & Keeps a few same friends & & & $-.639(.440)$ & .404 \\
\hline
\end{tabular}




\begin{tabular}{|c|c|c|c|c|c|c|}
\hline Item9 & \multicolumn{2}{|l|}{ Gets bored easily } & \multicolumn{3}{|c|}{$-.467(.433)$} & .349 \\
\hline Item10 & Uses or cons others & & & & $.713(.766)$ & .492 \\
\hline Item8 & Brags about accomplishments & & & & $.572(.598)$ & .346 \\
\hline Item6 & Lies easily and skillfully & & & & $.524(.648)$ & .406 \\
\hline Item 14 & Charming in insincere ways & & .339 & & $.479(.428)$ & .333 \\
\hline Item2 & Engages in illegal activities & & & & $.464(.578)$ & .257 \\
\hline Item5 & Shallow emotions & & & & $.410(.646)$ & .233 \\
\hline Eigenv & & 3.097 & 1.846 & 1.361 & 1.128 & \\
\hline explain & Variance & $15.485 \%$ & $9.230 \%$ & $6.807 \%$ & $5.641 \%$ & \\
\hline
\end{tabular}

Note. Factor loadings <.30 are not shown. Values in the brackets were factor loading obtained from the results of CFA; APSD-SR = Antisocial Process Screening Device-Self-Report; IMP = Impulsivity; CU = Callous-Unemotional; ASO = Asocial Behavior; NAR = Narcissism; COMM

$=$ Communalities; $\mathrm{R}=$ Reverse Scored 
Table 2

Goodness-of-fit indices for the three tested models of the APSD-SR

\begin{tabular}{llllll}
\hline MODEL & WLSMV $\chi^{2}$ & $d f$ & TLI & CFI & RMSEA (90\% CI) \\
\hline Single factor & $395.418^{* *}$ & 152 & .736 & .765 & $.057[.050 .063]$ \\
Three factor & $348.684 * *$ & 132 & .709 & .749 & $.057[.050 .065]$ \\
Four factor & $263.590 * *$ & 146 & .869 & .888 & $.040[.032 .048]$ \\
Second order & $277.365 * *$ & 148 & .856 & .875 & $.042[.034 .049]$ \\
\hline
\end{tabular}

Note. $* * p<.001 ;$ WLSMV $=$ The Robust Weighted Least Squares Estimation; $\chi^{2}=$

Chi-square Value; $d f=$ Degrees of Freedom; TLI = Tucker-Lewis Index; CFI = Comparative Fit Index; RMSEA = Root Mean Square Error of Approximation; 90\% $\mathrm{CI}=90 \%$ Confidence Interval for RMSEA 
Table 3

Descriptive Statistics of all scales included

\begin{tabular}{|c|c|c|c|c|c|}
\hline variables & $M$ & $S D$ & $\mathrm{~N}$ & Alpha & MIC \\
\hline APSD total & 10.190 & 3.910 & 19 & .637 & .092 \\
\hline IMP & 4.040 & 1.979 & 6 & .575 & .186 \\
\hline $\mathrm{CU}$ & 1.814 & 1.465 & 4 & .504 & .204 \\
\hline NAR & 1.330 & 1.461 & 6 & .556 & .181 \\
\hline ASO & 3.050 & 1.483 & 3 & .416 & .197 \\
\hline YPI total & 36.707 & 16.488 & 50 & .892 & .153 \\
\hline Dishonest charm & 2.100 & 2.429 & 5 & .717 & .360 \\
\hline Grandiosity & 3.160 & 2.780 & 5 & .720 & .347 \\
\hline Lying & 2.740 & 2.691 & 5 & .704 & .325 \\
\hline Manipulation & 1.700 & 2.139 & 5 & .693 & .327 \\
\hline Remorselessness & 3.250 & 2.551 & 5 & .573 & .212 \\
\hline Unemotionality & 5.710 & 2.633 & 5 & .469 & .152 \\
\hline Callousness & 3.338 & 2.301 & 4 & .522 & .203 \\
\hline Thrill-seeking & 5.380 & 2.975 & 5 & .664 & .279 \\
\hline Impulsiveness & 5.850 & 2.990 & 5 & .636 & .261 \\
\hline Irresponsibility & 2.470 & 2.199 & 5 & .496 & .181 \\
\hline YSR total & 9.330 & 6.927 & 33 & .871 & .180 \\
\hline
\end{tabular}




\begin{tabular}{lccccc} 
RB & 2.280 & 2.297 & 13 & .672 & .166 \\
AGG & 7.030 & 5.205 & 20 & .841 & .219 \\
RPQ total & 7.400 & 5.276 & 23 & .859 & .226 \\
Proactive & 1.510 & 2.389 & 12 & .807 & .279 \\
Reactive & 5.920 & 3.537 & 11 & .797 & .261 \\
\hline
\end{tabular}

Note. $\mathrm{N}=$ number of items; APSD = Antisocial Process Screening Device; IMP =

Impulsivity; $\mathrm{CU}=$ Callous-Unemotional; $\mathrm{NAR}=$ Narcissism; $\mathrm{ASO}=$ Asocial behavior; YPI = Youth Psychopathic Traits Inventory; YSR = The Youth Self-Report; $\mathrm{RB}=$ Rule-Breaking behavior; $\mathrm{AGG}=$ Aggressive behavior; $\mathrm{RPQ}=$ The Reactive Proactive Aggression Questionnaire. MIC = Mean Interitem Correlation. 
Table 4

Correlations between the APSD scores and YPI, YSR, and PRQ

\begin{tabular}{|c|c|c|c|c|c|}
\hline & IMP & $\mathrm{CU}$ & NAR & ASO & APSD total \\
\hline $\mathrm{CU}$ & .036 & & & & \\
\hline NAR & $.404 * *$ & $.092 * *$ & & & \\
\hline ASO & $.291 * *$ & $-.069 * *$ & $.179 * *$ & & \\
\hline APSD total & $.774 * *$ & $.392 * *$ & $.672 * *$ & $.565^{* *}$ & \\
\hline Dishonest charm & $.320 * *$ & $.062 * *$ & $.466^{* *}$ & $.167 * *$ & $.429 * *$ \\
\hline Grandiosity & $.229 * *$ & -.020 & $.328 * *$ & $.079 * *$ & $.255^{* *}$ \\
\hline Lying & $.395^{* *}$ & $.126 * *$ & $.495 * *$ & $.182 * *$ & $.505^{* *}$ \\
\hline Manipulation & $.282 * *$ & $.107 * *$ & $.452 * *$ & $.101 * *$ & $.389 * *$ \\
\hline Remorselessness & $.320 * *$ & $.155^{* *}$ & $.330 * *$ & $.158 * *$ & $.401 * *$ \\
\hline Unemotionality & $.176^{* *}$ & .026 & $.229 * *$ & $.131 * *$ & $.230 * *$ \\
\hline Callousness & .020 & $.364 * *$ & $.131 * *$ & $-.050 *$ & $.168 * *$ \\
\hline Thrill-seeking & $.467 * *$ & .004 & $.310 * *$ & $.223 * *$ & $.430 * *$ \\
\hline Impulsiveness & $.555^{* *}$ & $.059 * *$ & $.295 * *$ & $.230 * *$ & $.497 * *$ \\
\hline Irresponsibility & $.419 * *$ & $.137 * *$ & $.352 * *$ & $.216^{* *}$ & $.477 * *$ \\
\hline YPI total & $.524 * *$ & $.169 * *$ & $.542 * *$ & $.241 * *$ & $.614 * *$ \\
\hline $\mathrm{RB}$ & $.413 * *$ & $.124 * *$ & $.433 * *$ & $.158 * *$ & $.485 * *$ \\
\hline AGG & $.517 * *$ & -.003 & $.437 * *$ & $.255^{* *}$ & $.521 * *$ \\
\hline YSR total & $.525^{* *}$ & .040 & $.473 * *$ & $.245^{* *}$ & $.554 * *$ \\
\hline
\end{tabular}




\begin{tabular}{llllll} 
Proactive & $.317 * *$ & $.223 * *$ & $.405 * *$ & .017 & $.397 * *$ \\
Reactive & $.549 * *$ & .079 & $.370 * *$ & $.177 * *$ & $.507 * *$ \\
RPQ total & $.519 * *$ & $.153 * *$ & $.437 * *$ & $.128 * *$ & $.528 * *$ \\
\hline
\end{tabular}

Note. *. Correlation is significant at the 0.05 level (2-tailed).

**. Correlation is significant at the 0.01 level (2-tailed).

APSD $=$ Antisocial Process Screening Device; IMP = Impulsivity; $\mathrm{CU}=$ Callous-Unemotional; NAR = Narcissism; ASO = Asocial behavior; YPI = Youth Psychopathic Traits Inventory; YSR = The Youth Self-Report; RB = Rule-Breaking behavior; $\mathrm{AGG}=$ Aggressive behavior; $\mathrm{RPQ}=$ The Reactive-Proactive Aggression Questionnaire. 
Table 5

Means, standard deviations, $t$-test and numbers for the APSD-SR by gender groups

\begin{tabular}{|c|c|c|c|c|c|c|}
\hline & \multicolumn{2}{|c|}{ Gender } & \multirow{2}{*}{\multicolumn{2}{|c|}{ Number }} & \multirow[b]{3}{*}{$t$} & \multirow[b]{3}{*}{$d$} \\
\hline & \multirow{2}{*}{$\frac{\text { Male }}{\text { Mean(SD) }}$} & \multirow{2}{*}{$\frac{\text { Female }}{\operatorname{Mean}(\mathrm{SD})}$} & & & & \\
\hline & & & Male & Female & & \\
\hline IMP & $4.13(1.96)$ & $3.95(2.02)$ & 776 & 773 & 1.75 & .09 \\
\hline $\mathrm{CU}$ & $2.07(1.51)$ & $1.62(1.44)$ & 774 & 775 & $5.95 * *$ & .30 \\
\hline NAR & $1.65(1.58)$ & $1.06(1.27)$ & 762 & 774 & $8.16^{* *}$ & .42 \\
\hline ASO & $3.01(1.50)$ & $3.24(1.46)$ & 780 & 782 & $-3.08^{*}$ & -.16 \\
\hline Total & $10.84(4.04)$ & $9.83(3.73)$ & 735 & 750 & $4.99 * *$ & .25 \\
\hline
\end{tabular}

Note. ${ }^{*}$ Correlation is significant at the 0.05 level (2-tailed).

** Correlation is significant at the 0.01 level (2-tailed).

APSD-SR = Antisocial Process Screening Device-Self-Report; IMP = Impulsivity; $\mathrm{CU}=$ Callous-Unemotional; $\mathrm{ASO}=$ Asocial behavior; NAR $=$ Narcissism $; t=$ value of t-test, $d=$ Cohen's $d$ 
